\title{
MODELLING NAIRA/POUNDS EXCHANGE RATE VOLATILITY: APPLICATION OF ARIMA AND GARCH MODELS
}

\author{
Saminu Umar \\ Department of Mathematics and Statistics \\ Umaru Ali Shinkafi Polytechnic, Sokoto, Nigeria
}

\author{
Abdulrashid M. Salihu \\ Department of Mathematics and Statistics \\ Umaru Ali Shinkafi Polytechnic, Sokoto, Nigeria
}

\author{
Shehu Sidi Abubakar \\ Department of Mathematics and Statistics \\ Umaru Ali Shinkafi Polytechnic, Sokoto, Nigeria
}

\author{
Zayyanu Umar \\ Department of Agricultural Science \\ Shehu Shagari Collage of Education, Sokoto, Nigeria
}

\begin{abstract}
This study aimed at modelling the daily Naira/Pound exchange rate volatility with ARIMA and GARCH type models with daily exchange rate ranging from June 2016 to July 2019 is obtained from Central Bank of Nigeria. The stationarity of the data series was checked using graphical analysis, Augmented Dickey Fuller (ADF) and Phillips-Perron (PP) tests, it was found out that the exchange rate series is not stationary, the return of the series was obtained and found out to be stationary. It was observed that ARIMA $(2,1,1)$ and $\operatorname{GARCH}(1,1)$ are the optimal with the highest log-likelihood and lowest AIC and BIC.
\end{abstract}

Keywords-Exchange rate, Volatility, Heteroscedasticity, GARCH

\section{INTRODUCTION}

Currency serves as a medium of exchange that simplifies transactions between variant individuals interacting in a marketplace. However, transactions between people who live in different countries are more complicated because of the existence of different mediums of exchange. Obafemi (2017) describe exchange rate as the price of one country's currency in relation to another country. It is the price in which one currency is exchange for another. It measures the domestic worth of an economy; in terms of the currencies of most industrialized countries such as United State of America Dollars, British Pound Sterling.

Exchange rate policy has been identified as one of the endogenous factors that can affect the economic performance of a nation. In Nigeria, the management of exchange rate is carried out by the Central Bank of Nigeria following the adoption of the structural adjustment program policy in 1986, the country has moved from a pegged or rigid exchange rate regime to a more flexible regime. Esam, (2017) in his work highlighted that, no exchange rate is 'clean or pure float', that is a situation where the exchange rate is left completely to be determined by market forces of demand and supply but rather the prevailing system is the managed float whereby the monetary authorities intervene periodically in the foreign exchange market of a country in order to attain some strategic objectives.

Time series is the record of outcomes of a variable according to time, the outcomes may be recorded daily, weekly, monthly, quarterly, yearly or at any other specified interval of time. It is known that time series data are volatile. Undoubtedly, daily exchange rate of one currency for another currency forms a time series. David et al, (2016) stress that a time series may be studied in order to obtain an appropriate model which may be necessary for planning purpose. For example, having an idea of the future exchange rate of a currency for another currency could help the country to guide against inflation, determine its balance of payments and formulate feasible economic policies, among other benefits.

The volatility of financial time series appears to change over time; one class of models that have been developed with a feature that accommodates the dynamics of conditional heteroscedasticity is the autoregressive conditional heteroscedasticity (ARCH) proposed by (Engle, 1982), it is widely adopted to describe and forecast time-varying volatility of financial assets, and extended to generalized autoregressive conditional heteroscedasticity (GARCH) by Bollerslev (1986) has been shown to be useful in modeling variance.

Several studies have applied the Box-Jenkins and GARCH models approach to model and forecast time series, some of these studies include; Shahla et al, (2012), the authors studied and modelled Monthly average foreign exchange rates of Pakistan using ARCH and GARCH models they found ARMA $(1,2)$ and GARCH $(1,2)$ to be best models in terms of fitting and forecasting power of the exchange rate return. Bala et al, (2013), examines monthly exchange-rate return for three major currencies in the Nigerian FX markets: The Naira/USD, Euro and BPS using variants of GARCH volatility models and compared estimates from these models, their study reveals that 


\section{International Journal of Engineering Applied Sciences and Technology, 2019 \\ Vol. 4, Issue 8, ISSN No. 2455-2143, Pages 238-242 \\ Published Online December 2019 in IJEAST (http://www.ijeast.com)}

TGARCH is the best fitting model for Euro, while ARCH and PARCH $(1,1)$ are the best fitting models for BPS return and Naira/USD returns. For the USD return model with volatility breaks, the best fitting model is the IGARCH. Suleiman et al, (2015), explored and developed the best ARIMA and GARCH models to efficiently forecast monthly crude oil price in Nigeria. The result of their empirical analysis reveals ARIMA $(3,1,1)$ and $\operatorname{GARCH}(2,1)$ as the best model for forecasting the crude oil price data series. The aim of this study is to develop time series models (ARIMA and GARCH models) for the Naira/Pounds exchange rate.

\section{MATERIAL AND METHODS}

\section{A. Data -}

The data for this study is of the daily official exchange rate of Nigerian naira per Sterling Pounds. The data is obtained from Central Bank of Nigeria (CBN) with sample period ranging from 20/6/2016 to 31/7/2019 consisting of a total of 747 observations. Econometric time series models ARIMA, ARCH and GARCH are applied to model the data.

\section{B. Autoregressive Integrated Moving Average (ARIMA) Models-}

A general notation for Autoregressive Integrated Moving Average (ARIMA) popularly known as Box-Jenkins Methodology (G. P. E. Box and G. M. Jenkins (1978)) is (ARIMA $(p, d, q)$ ) where $p$ denotes the number of autoregressive terms, $q$ denotes the number of moving average terms and $d$ denotes the number of times a series must be differenced to induce stationarity.

$$
\phi(\mathrm{B})(1-B)^{d} X_{t}=\mu+\theta(B) \varepsilon_{t}
$$

Where $\phi(B)$ and $\theta(B)$ are polynomials of degrees $\mathrm{p}$ and qrespectively and $(1-B) d=\nabla^{d}$ is the differencing operator and represents the order of differencing the series and $\varepsilon_{t}$ is independently and normally distributed with zero mean and constant variance.

\section{Autoregressive Autoregressive Conditional Hetroskedasticity (ARCH) Models-}

The first model that provides a systematic framework for volatility modeling is the Autoregressive Conditional Heteroskedastic (ARCH) model of Engle (1982), he proposed a model in which the conditional variance of a time series is a function of past shocks; the model provided a rigorous way of empirically investigating issues involving volatility of economic variables.

$\mathrm{ARCH}(\mathrm{m})$ model assumes that

$$
\begin{gathered}
y_{\mathrm{t}}=\sigma_{\mathrm{t}} \varepsilon_{\mathrm{t}} \\
\sigma_{\mathrm{t}}^{2}=\alpha_{0}+\underset{\alpha_{1} \mathrm{a}_{\mathrm{t}-1}^{2}+\cdots+\alpha_{\mathrm{m}} \mathrm{a}_{\mathrm{t}-\mathrm{m}}^{2}}{\sigma_{\mathrm{t}}^{2}}=\alpha_{0}+\sum_{\mathrm{i}=1}^{m} \alpha_{1} \mathrm{a}_{\mathrm{t}-\mathrm{i}}^{2}
\end{gathered}
$$

Where $\left\{\varepsilon_{\mathrm{t}}\right\}$ is a sequence of independent and identically distributed (iid) random variables with mean zero $\left[E\left(\varepsilon_{\mathrm{t}}\right)=\right.$ $0]$ and variance $1\left[E\left(\varepsilon_{t}^{2}\right)=1\right]$, i.e. the random variable $\left\{\varepsilon_{\mathrm{t}}\right\}$ is a White noise process, $\alpha_{0}>0$, and $\alpha_{i} \geq 0$ for $i>0$. The coefficients $\alpha_{\mathrm{i}}$ must satisfy some regularity conditions to ensure that the unconditional variance of $\alpha_{\mathrm{t}}$ is finite.

\section{Generelized Autoregressive Autoregressive Conditional Hetroskedasticity (ARCH) Models-}

Bollerslev (1986) proposed a useful extension known as the generalized ARCH (GARCH) model. For a log return series $y_{t}$, we assume that the mean equation of the process can be adequately described by an ARMA model. Let $a_{t}=y_{t}-\mu_{t}$ be the mean-corrected $\log$ return. Then $\mathrm{a}_{\mathrm{t}}$ follows a $\mathrm{GARCH}(\mathrm{m}, \mathrm{s})$ (where $\mathrm{m}$ is the order of the GARCH term $\sigma$ and $s$ is the order of the ARCH term $\varepsilon_{\mathrm{t}}$ ) model if

$$
\begin{gathered}
\sigma_{\mathrm{t}}^{2}=\mathrm{a}_{0}+\mathrm{a}_{1} \varepsilon_{\mathrm{t}-1}^{2}+\cdots \mathrm{a}_{\mathrm{m}} \varepsilon_{\mathrm{t}-\mathrm{m}}^{2}+\beta_{1} \sigma_{\mathrm{t}-1}^{2}+\mathrm{L}+\beta_{\mathrm{s}} \sigma_{\mathrm{t}-\mathrm{s}}^{2} \\
\sigma_{\mathrm{t}}^{2}=\alpha_{0}+\sum_{\mathrm{i}=1}^{\mathrm{m}} \alpha_{\mathrm{i}} \varepsilon_{\mathrm{t}-\mathrm{i}}^{2}+\sum_{\mathrm{j}=1}^{\mathrm{s}} \beta_{\mathrm{j}} \sigma_{\mathrm{t}-\mathrm{j}}^{2}
\end{gathered}
$$

where again $\left\{\varepsilon_{\mathrm{t}}\right\}$ is a sequence of iid random variables with mean 0 and variance $1, \alpha_{0}>0, \alpha_{i} \geq 0, \beta_{j} \geq 0$, and $\sum_{i=1}^{\max (m, s)} \quad\left(\alpha_{i}+\right.$ $\left.\beta_{j}\right)<1$. It is observed that $\alpha_{i}=0$ for $i>m$ and $\beta_{j}=0$ for $j>s$. The latter constraint on $\alpha_{\mathrm{i}}+\beta_{\mathrm{j}}$ implies that the unconditional variance of $\mathrm{a}_{\mathrm{t}}$ is finite, whereas its conditional variance $\sigma_{\mathrm{t}}^{2}$ evolves over time. As before, $\varepsilon_{\mathrm{t}}$ is assumed to be White noise. Equation (3.4) reduces to a pure $\mathrm{ARCH}(\mathrm{m})$ model if $\mathrm{s}=0$.

\section{RESULT AND DISCUSSION}

Having explored the theory of ARIMA, ARCH and GARCH models in the preceding section, this section provides an empirical analysis of the daily exchange rate data of Nigerian Naira and Serling pounds. Fig. 1 shows the graphical analysis of the exchange rate series, it is observed that there is upward and downward trend indicating volatility clustering which suggests the exchange rate is nonstationary. It is important to confirm whether the data is stationary before using the time series models like Autoregressive Integrated Moving Average (ARIMA), Autoregressive Conditional Heteroscedasticity (ARCH), Generalized Autoregressive Conditional Heteroscedasticity (GARCH)

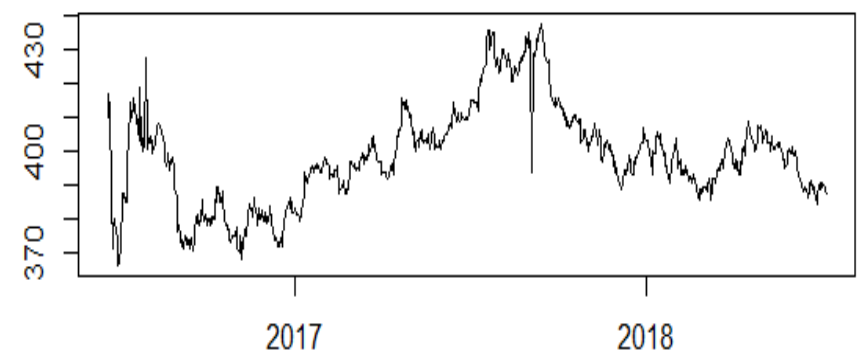

Fig.1: Time series plot of daily exchange rate

The Augmented Dickey Fuller (ADF) and PhilipPerron (PP) tests were performed, the result is presented in $t$ able1, since the P-value for both tests is greater than the critical value, we do not reject the null hypothesis of the presence of unit root in the series and conclude that the exchange rate series 
is nonstationary, this is in line with the observation from the graphical analysis. To transform the nonstationary exchange rate series, we obtain daily returns calculated as; $r_{t}=$ $\ln \left(\frac{p_{t}}{p_{t-1}}\right) \times 100$ where $p_{t}$ is the daily closing price at time $\mathrm{t}$, for $\mathrm{t}=1,2 .$. and $\ln$ is the natural $\log$

Table 1: Unit root test

\begin{tabular}{|l|l|}
\hline Test & Exchane_data \\
\hline Augmented Dickey-Fuller & $\mathbf{- 0 . 4 5 1 7}$ \\
P-Value & $\mathbf{0 . 5 1 4}$ \\
\hline Phillips-Perron Test & $\mathbf{- 3 . 0 9 7 7}$ \\
P-Value & $\mathbf{0 . 1 1 3 7}$ \\
\hline
\end{tabular}

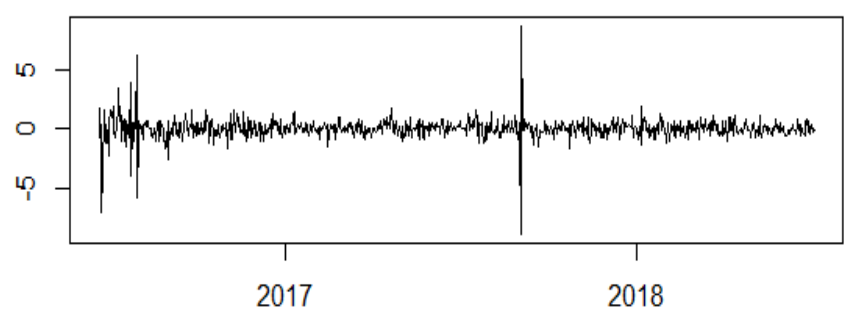

Fig. 2: Return plot of exchange rate.

The Summary Statistics for the returns are shown in table 2. It is noted that the returns series has a mean close to zero, the standard deviation is high which indicates high level of fluctuation in exchange rate return. There is also evidence that the exchange return distribution is leptokurtic and negatively skewed suggesting the exchange rate return is not normally distributed as confirmed by the Jarque-Bera and Shapiro-Wilk tests with P-values less than the critical value, The ADF and PP tests were also applied to the exchange return series both tests indicate that the return series is stationary.

Table 2: Summary Statistics

\begin{tabular}{|l|l|}
\hline Statistic & Exchange_ret \\
\hline Mean & $\mathbf{- 0 . 0 0 7 4 6 6 7 4 1}$ \\
\hline Std. Dev & $\mathbf{0 . 8 8 9 6 0 6 7}$ \\
\hline Minimum & $\mathbf{- 8 . 9 2 6 1 3 8}$ \\
\hline Maximum & $\mathbf{3 7 . 5 9 2 1 7}$ \\
\hline Skewness & $\mathbf{- 0 . 7 7 7 4 1 6 5}$ \\
\hline Kurtosis & $\mathbf{3 6 . 3 8 0 9 2}$ \\
\hline Jarque-BeraTest & $\mathbf{2 4 3 6 5 0 4 . 9 6 1 9}$ \\
P-value & $\mathbf{2 . 2 e - 1 6}$ \\
\hline Shapiro-Wilk Test & $\mathbf{0 . 2 6 5 8}$ \\
P-value & $\mathbf{2 . 2 e - 1 6}$ \\
\hline Augmented Dickey-Fuller Test & $\mathbf{- 1 2 . 2 7 4}$ \\
PValue & $\mathbf{0 . 0 1}$ \\
\hline
\end{tabular}

\begin{tabular}{|l|l|}
\hline Phillips-Perron Test & -37.467 \\
P-value & 0.01 \\
\hline
\end{tabular}

\section{A. ARIMA Model fitting-}

To start with, the conditional mean process of the $\mathrm{e}$ xchange rate data is modelled with ARIMA, among different A RIMA models applied, ARIMA $(2,1,1)$ appears to be optimal on the basis of possessing minimum AIC and BIC. Estimates o $\mathrm{f}$ the parameters of the model are shown in table 3 , both the co efficients of AR (2) and MA (1) are statistically significant, in addition the forecast performance of the fitted ARIMA model $i$ $\mathrm{s}$ investigated through mean error (ME), mean absolute error ( MAE), root mean square error (RMSE), based on the observed values the forecast performance indicators, the forecasted valu es are close to the actual values which implies that the model fi ts the data.

Table 3: Result of ARIMA $(2,1,1)$

\begin{tabular}{|c|c|c|c|c|}
\hline Parameter & $\begin{array}{l}\text { Estim } \\
\text { ate }\end{array}$ & $\begin{array}{l}\text { Std. Err } \\
\text { or }\end{array}$ & $\begin{array}{l}\text { z valu } \\
\text { e }\end{array}$ & $\operatorname{Pr}(>|z|)$ \\
\hline ar1 & $\begin{array}{l}\mathbf{0 . 7 5 3 9} \\
36\end{array}$ & $\begin{array}{l}\mathbf{0 . 0 4 5 1 8} \\
4\end{array}$ & $\begin{array}{l}16.685 \\
9\end{array}$ & $<2.2 \mathrm{e}-16$ \\
\hline ar2 & $\begin{array}{l}0.1661 \\
68\end{array}$ & $\begin{array}{l}0.03860 \\
4\end{array}$ & 4.3044 & $1.675 \mathrm{e}-05$ \\
\hline ma1 & $\begin{array}{l}-0.964 \\
640\end{array}$ & $\begin{array}{l}\mathbf{0 . 0 2 6 0 7} \\
7\end{array}$ & $\begin{array}{l}-36.99 \\
17\end{array}$ & $<2.2 \mathrm{e}-16$ \\
\hline log likelihood & \multicolumn{4}{|c|}{-1996.31} \\
\hline AIC & \multicolumn{4}{|l|}{4000.62} \\
\hline BIC & \multicolumn{4}{|l|}{4019.09} \\
\hline ME & \multicolumn{4}{|c|}{0.1048233} \\
\hline MAE & \multicolumn{4}{|c|}{1.769403} \\
\hline RMSE & \multicolumn{4}{|c|}{4.731945} \\
\hline
\end{tabular}

\section{A. ARIMA Model cheking -}

Having chosen the best ARIMA model, the adequacy of the model is checked by analyzing the residuals, we examine whether the squares of residuals are a sequence of white noise and the residuals are homoscedastic of arch effects. The ARCH family of models requires the presence of 'ARCH effect' in the residuals in order to be applied. There are various tests including Portmanteau Q test, Lagrange Multiplier (LM), autocorrelation and partial autocorrelations, Jarque-Bera test, and Ljung-Box test; the Portmanteau Q test and Lagrange Multiplier (LM) test were applied to test the whether the residuals are white noise and the presence of $\mathrm{ARCH}$ effect respectively. The diagnostic test result presented in table 5 shows that the model has passed the diagnostic test of normality and evidence of remaining ARCH effect. The confirmation of the presence of $\mathrm{ARCH}$ effects indicates that volatility in the exchange return series is time varying, therefore the conditional heteroscedasticity in estimated ARIMA errors is modeled using GARCH model 


\section{International Journal of Engineering Applied Sciences and Technology, 2019 \\ Vol. 4, Issue 8, ISSN No. 2455-2143, Pages 238-242 \\ Published Online December 2019 in IJEAST (http://www.ijeast.com)}

Table 4: Result of ARMA $(2,1)$ model checking

\begin{tabular}{|l|l|l|}
\hline Test & Test statistic & $\mathbf{P}$ \\
\hline Portmanteau-Q test & $\mathbf{1 3 3}$ & $<\mathbf{0 . 0 0 1}$ \\
\hline Lagrange-Multiplier test & $\mathbf{5 5 0 . 3}$ & $<\mathbf{0 . 0 0 1}$ \\
\hline
\end{tabular}

\section{B. GARCH Model fitting -}

Among different models applied, GARCH $(1,1)$ ap pears to be optimal on the basis of possessing minimum AIC a nd BIC. The estimates of the parameters of the model are prese nted in table 5 The estimated parameters are statistically signif icant.

Table 5: Result of GARCH $(1,1)$

\begin{tabular}{|c|c|c|c|c|}
\hline Parameter & Estimate & Std. Err & t val & $\operatorname{Pr}(>|t|)$ \\
\hline Mu & -0.16550 & 0.10167 & -1.628 & 0.10356 \\
\hline Omega & 0.52270 & 0.16262 & 3.214 & 0.00131 \\
\hline alpha1 & 0.24740 & 0.05233 & 4.728 & $2.27 e-06$ \\
\hline beta1 & 0.77242 & 0.03190 & 24.213 & $<2 \mathrm{e}-16$ \\
\hline LogLikelihood & \multicolumn{4}{|c|}{-2.516144} \\
\hline AIC & \multicolumn{4}{|c|}{5.042983} \\
\hline BIC & \multicolumn{4}{|c|}{5.067675} \\
\hline ME & \multicolumn{4}{|c|}{0.07080631} \\
\hline MAE & \multicolumn{4}{|c|}{0.3264584} \\
\hline RMSE & \multicolumn{4}{|c|}{0.3891713} \\
\hline
\end{tabular}

\section{GARCH Model checking -}

The diagnostic tests results presented in table 6indi cate that the fitted GARCH $(1,1)$ model has adequately captur ed the volatility and there is no ARCH effect left in the residua ls, also the model has passed the diagnostic test of normality. T he forecast performance of the fitted GARCH model is investi gated through mean error (ME), mean absolute error (MAE), $r$ oot mean square error (RMSE), based on the observed values $t$ he forecast performance indicators we can say that the forecast ed values are close to the actual values and that the model fits $t$ he data, hence good for forecasting purpose along with capturi ng the volatility.

Table 6: Result of GARCH $(1,1)$ model checking

\begin{tabular}{|l|l|l|}
\hline Test & Statistic & p-Value \\
\hline Jarque-Bera Test & $\mathbf{4 4 8 2 7 . 7 8}$ & $<\mathbf{0 . 0 0 1}$ \\
\hline Shapiro-Wilk Test & $\mathbf{0 . 8 2 8 4 3 0 2}$ & $<\mathbf{0 . 0 0 1}$ \\
\hline Ljung-Box Test & $\mathbf{1 1 . 8 5 3 3}$ & $\mathbf{0 . 2 9 4 9 9 4 9}$ \\
\hline LM Arch Test & $\mathbf{1 . 0 0 8 0 9 7}$ & $\mathbf{0 . 9 9 9 9 8 5 2}$ \\
\hline
\end{tabular}

\section{CONCLUSION}

This study focuses on developing the best models to efficiently forecast the exchange rate of Nigerian Naira and Sterling Pounds using ARIMA and GARCH models. Daily exchange rate ranging from June 2016 to July 2019 is obtained from Central Bank of Nigeria for this purpose After the data was subjected to various tests it was discovered that exchange rate series is nonstationary, the return of the exchange series was obtained and appears to be stationary. Further empirical analysis led to choosing ARIMA $(2,1,1)$ and $\operatorname{GARCH}(1,1)$ models as the optimal in terms of fitting and forecasting the daily exchange rate of Nigerian Naira and Sterling Pounds.

\section{ACKNOWLEDGEMENTS}

I would like to thank Malan Ibrahim Abubakar Zarumias as well as my colleagues for their help during the course of this work. We also acknowledge the authors whose works were cited in this paper and International Journal of Engineering Applied Sciences and Technology for the opportunity.

\section{REFERENCE}

[1] Aikake, H. (1974), "A new look at the statistical model identification", IEEE Transactions on Automatic Control, vol. 19(6). (pp. 716-723). DOI: 10.1109/TAC.1974.1100705

[2] Bala Dahiru A. Asemota, Joseph O. (2013), Exchangerates volatility in Nigeria: Application of GARCH models with exogenous break, CBN Journal of Applied Statistics, Vol. 4(1). (pp. 89-116)

[3] Bollerslev Tim (1986). "Generalized Autoregressive Conditional Heteroskedasticity", Journal of Econometrics, 31: (pp. 307-327).

[4] Box, G. E. P., and Jenkins, G. M. (1976), Time Series Analysis: Forecasting and Control, revised edition, San Francisco: Holden Day.

[5] Chrysogonus Chinagorom Nwaigwe, Godswill Uchenna Atuzie, Iheanyi Chinedu Obinwanne,Chukwudi Justin Ogbonna (2018). A time series analysis of daily exchange rate of Ddollar to Naira from 2016-2017 (Recession period) International Journal of Scientific \& Engineering Research Vol 9 (7). (pp. 2229-5518).

[6] David, R. O., Dikko H. G. and Gulumbe S. U. (2016). Modeling Volatility of the Exchange Rate of the Naira to Major Currencies, C. B. N. Journal of Applied Statistics, Vol. 7(2) (Pg 159-187).

[7] Dickey, D. A., and Fuller, W. A. (1979), „Distribution of the Estimators for Autoregressive Time Series with a Unit Roote", Journal of the American Statistical Association, 74,(Pg 427-31).

[8] Engle, Robert F. (1982). "Autoregressive Conditional Heteroscedasticity with Estimates of Variance of United 
Kingdom Inflation", Econometrica Vol . 50(4) (pp. 9871008).

[9] Esam M. (2017). "Time Series Analysis - part 2". Islamic University of Gaza - Department of Mathematics

[10] Ljung, G.M and Box, G.E.P (1978), On a measure of lack of fit in time series models, Biometrika Vol. 65 (pp. 297303)

[11] Ajao I.O; Obafemi O.S and Bolarinwa F. A. (2017). Modelling Dollar-Naira Exchange Rate in Nigeria. National statistical society vol. 1. DOI: https://doi.org/10.14738/tmlai.74.6566

[12] Phillips, P. C. B., Perron, P. (1988) Testing for a unit root in a time series regression. Biometrika, Vol. 75, No. 2, (pp. 335-346).

[13] ShahlaRamzan, ShumilaRamzan, Faisal MaqboolZahid(2012), Modeling and forecasting exchange rate dynamics in pakistan using arch family of models, Electronic Journal of Applied Statistical Analysis, Vol. 5(1). (pp $15-29)$

[14] Suleiman S., Alabi, M. A, Issa, Suleman, U. Usman, Umar Adamu (2015), Modeling and Forecasting the Crude Oil Price in Nigeria, International Journal of Novel Research in Marketing Management and Economics, Vol. 2(1). (pp. 1-13)

[15] Wit, Ernst; Edwin van den Heuvel; Jan-Willem Romeyn (2012). "'All models are wrong...': an introduction to model uncertainty". Statistica Neerlandica. Vol 66 (3). 217-236. DOI: $10.1111 /$ j.1467-9574.2012.00530 